\title{
ConClusion
}

These then are some of the developments which you should keep in mind as you deliberate in your discussion groups in this conference. I could have presented a number of others. These are only the more important ones. Others will come to you as you discuss the problems in the various study groups. May I remind you again of the dominating purpose of junior high-school education; namely, that it is our job to develop the best educational program possible to meet the needs, the abilities, and the interests of early adolescents. All your discussions during the next two days should be directed toward ways of achieving that goal.

\section{Planning for Evaluation in the Junior High School}

\author{
Gail Shannon
}

$I_{N}$

N OUR present-day pattern of living, we are regularly asked, if not forced, to place a value upon many things. Perhaps it is the cut of meat at the super market, a suit of clothes which has caught our eye, a new car, or any of a host of other items. In many of these situations, the trade competition attempts to help us with our evaluation by producing all manner of research ( $I$ use this term loosely) to prove which is the best car, cigarette, et cetra, emphasizing such well-known slogans as "They said it couldn't be done" and "Don't be half safe." We must thus face the question "How do we determine the true value of a product or a process?"

In a more solemn vein, it is my desire to propose that we consider seriously the placing of values upon our educational system-its goals, curriculum, facilities, and its staff. I should like, in this discussion to focus upon a very important segment of our school system-the junior high school-and I shall examine the topic, "Planning for Evaluation in the Junior High School."

Before we can plan, or as an initial part of our planning, we must determine what is meant by the term "evaluation." Evaluation implies the systematic and objective gathering and treatment of data. In its broad context, evaluation is a several-step process. It may be narrow in scope or it may be all-inclusive. Evaluation is a process of inquiry which attempts to place a value or values upon a situation or thing by selecting standards to be used as criteria to be applied to the situation or thing

Gail Shannon is Associate Professor and Assistant Dean in the College of Education, University of Oklahoma, Norman, Oklahoma. 
under consideration. In this day when there is open season on criticism of public education, it is the role of evaluation to provide valid evidence of the quality of accomplishment and progress being made in our schools. Let us now consider basic steps which a junior high-school administration and staff must take in planning for evaluation.

\section{STEP 1. Why are we evaluating?}

This point is often not clear to many staff members. There must be careful planning by both administration and staff in order that the purposes of evaluation are clearly understood. Are we evaluating because the superintendent or principal decided it should be done or has our decision to evaluate been cooperatively derived with clearly stated objectives? Although we sometimes evaluate to gain admission to accrediting associations, I am certain that the accepted purposes should be much more in keeping with our concern for identifying the progress made and in making value assessments. In common language, we need to find out what we have done in an educational situation during a given period and then determine the quality of the accomplishment.

It is also important to include students, parents, and the community in this first step. Much misunderstanding and adverse criticism may well be avoided by the proper communication of information in this area.

\section{STEP 2. What will be the scope of the evaluation?}

Will it be all-inclusive and consider all aspects of the school-pupil characteristics, philosophy, school community, school plant, activities, program of studies, administration, teaching staff, guidance, and library? Or will it be limited to one element of the total school or even one subject in the program of studies? This question must be considered carefully since its answer affects personnel to be involved, time allotments, and financial commitments.

\section{STEP 3. Who will be involved in this process?}

In a comprehensive evaluation process careful attention should be given to the defining of responsibilities and to the identification of staff and administrative personnel who will be most effective in completing the designated aspects of the process. Committee groups are frequently used with a planned schedule of meetings plus a series of full-staff sessions where committees may make reports and secure staff reaction in the form of approval or disapproval of tentative conclusions presented.

\section{STEP 4. What evaluative instruments will be used?}

The quality of the end product depends significantly upon the validity and reliability of the instruments selected for use in the process. Since this topic will be discussed in another session, I will comment only that a staff planning to engage in evaluation should examine all available and appropriate instruments. In some situations it may even be necessary that original instruments be designed and developed. 


\section{Step 5. Group orientation}

Once committee appointments have been made and all phases of the evaluation have been adequately covered, it is quite desirable to schedule a general orientation meeting to examine such elements as:

a. The materials to be used

b. Frequency and place of both general and committee meetings

c. Secretarial assistance available for the preparation of committee findings

d. Over-all length of time to be given to the project (6 months, 1 year, etc.)

e. Sequence to be considered in developing the various sub-areas of the project (It is often desirable if not essential to consider areas such as philosophy and purposes and school community first in order by the total staff before undertaking other areas.)

f. It is usually desirable to establish a date on which each sub-committee report should be completed and presented to the total staff.

\section{STEP 6. How will the findings be analyzed and interpreted?}

It is easy to become quite impressed with a sizeable volume of data and yet be most frustrated during attempts to analyze, interpret, and draw proper conclusions. Considering the scope of the evaluative process in which we are engaged, decisions must be made regarding analysis patterns which will be used and as to how much and what types of statistical data will be compiled. A pattern must also be established for the preparation of interpretations concerning the various parts of the data. I remember one staff group who spent long hours in interpretation and in securing majority staff approval for each concluding statement.

Even though much of the analysis, intepretation, and development of conclusions will be done by sub groups, it is certainly wise to present such findings for review by the total staff in order that unification of the total project may be maintained.

STEP 7. What will we do with our findings after the project is completed?

The implementation of decisions resulting from the conclusions developed by the project is a most significant aspect of evaluation. Reduced to an operation level, we must ask, "What will this school unit do in moving toward those improvements determined by the project?" Some decisions will demand further study and the gathering of additional data of a different nature; while other decisions will involve considerations relating to staff personnel, physical facilities, student grouping, schedule changes, and many other factors relating to the school and its program. It is fundamental that careful planning must be done before beginning an evaluation project in your school. It is equally important that consideration be given to the follow-up and implementation of the significant findings. 


\section{SUMMARY}

In summarizing, may I suggest some barriers to evaluation and then attempt to restate the "why" of evaluation in terms of goals of evaluation for the junior high school.

\section{Barriers}

1. An initial barrier to evaluation in many instances is that insufficient planning and organization has taken place.

2. Frequently, staff members may be a barrier to evaluation in that they do not understand or accept the basic values of evaluation and thus are prone to be unenthusiastic, if not outwardly opposed, to the proposal.

3. Administrators may oppose the evaluation project because of lack of faith in the ability of staff people to participate and to produce logical and intelligent findings. Fear of community resistance and pressure may also be a contributing factor.

4. Community members may be barriers in that they oppose both time and money spent in carrying out the project.

Planning for evaluation at any school level must take cognizance of the steps of sound organization and must proceed so as to eliminate or minimize those elements which may serve to block the progress of the project.

\section{Goals:}

1. To re-examine logically the philosophy and purposes of the junior high school

2. To involve administration, staff, students, and community in a cooperative, systematic study of the total school and its program

3. To produce information from which judgments may be drawn and conclusions be reached

4. To set forth qualitative recommendations for the improvement of the educational program of the school

5. To educate better the total community as to the unique role of the junior high school as a part of our total educational system

May I repeat in closing that, for the process of evaluation to anticipate maximum success, it is imperative that a most thorough job of planning be done-one that will consider all personnel, the time element, physical resources, and financial needs. I urge you to plan carefully, plan adequately as you engage in evaluation in your junior high school. 